\title{
Monitoring dan Evaluasi Budaya Keselamatan Pasien
}

\author{
Nikita Gina Chesena Sembiring \\ nikitagina.ng@gmail.com
}

\section{LATAR BELAKANG}

Kementerian Kesehatan Republik Indonesia telah mengeluarkan peraturan Menteri Kesehatan Nomor 11 tahun 2017 tentang keselamatan pasien di Rumah Sakit. Peraturan ini ini menjadi tonggak utama operasionalisasi keselamatan pasien di rumah sakit seluruh Indonesia. Banyak rumah sakit di Indonesia yang telah berupaya membangun dan mengembangkan keselamatan pasien, namun upaya tersebut dilaksanakan berdasarkan pemahaman manajemen terhadap keselamatan pasien. Peraturan menteri ini memberikan panduan bagi manajemen Rumah Sakit agar dapat menjalankan spirit keselamatan pasien secara utuh.

Keselamatan menjadi isu global dan terangkum dalam 5 isu penting yang terkait di rumah sakit yaitu keselamatan pasien, keselamatan pekerja atau petugas kesehatan, keselamatan bangunan dan peralatan di rumah sakit yang bisa berdampak terhadap keselamatan pasien dan petugas. Keselamatan lingkungan yang berdampak terhadap pencemaran lingkungan dan keselamatan bisnis rumah sakit yang terkait dengan kelangsungan hidup rumah sakit.

Keselamatan pasien merupakan prioritas utama untuk dilaksanakan terkait dengan isu mutu dan citra perumahsakitan. Keselamatan pasien adalah suatu sistem yang membuat asuhan pasien lebih aman, meliputi asesmen risiko Identifikasi dan pengelolaan risiko pasien, pelaporan dan analisis insiden, kemampuan belajar dari insiden dan tindak lanjutnya, serta implementasi solusi untuk meminimalkan timbulnya risiko dan mencegah terjadinya cedera yang disebabkan oleh kesalahan akibat melaksanakan suatu tindakan atau tidak mengambil tindakan yang seharusnya diambil (Permenkes, 2011).

Standar keselamatan pasien dipakai sebagai acuan bagi fasilitas pelayanan kesehatan dalam melaksanakan pelayanan kesehatan, mengingat masalah keselamatan pasien merupakan masalah yang perlu ditangani segera. Standar budaya keselamatan pasien ini mencakup hak sebagai pasien, mendidik kepada pasien dan keluarga pasien, keselamatan pasien dan kesinambungan terhadap pelayanan kesehatan, peran kepemimpinan dalam 
meningkatkan keselamatan pasien, mendidik staf tentang keselamatan pasien, komunikasi merupakan peningkatan budaya kerja dalam melakukan Monitoring evaluasi dan program peningkatan budaya keselamatan kepada pasien (Morello, 2014).

Rumah Sakit harus mampu memberikan perlindungan terhadap keselamatan pasien, masyarakat, lingkungan rumah sakit, serta sumber daya manusia yang ada titik paradigma baru dalam sistem akreditasi KARS versi 2012, mengarahkan seluruh kegiatan pelayanan rumah sakit agar mampu memberikan pelayanan yang memenuhi standar kualitas serta jaminan rasa aman dan perlindungan terhadap dampak pelayanan yang diberikan dalam rangka pemenuhan hak-hak masyarakat akan pelayanan yang berkualitas serta aman.

Upaya yang dapat dilakukan dalam peningkatan mutu pelayanan kesehatan adalah dengan budaya keselamatan pasien. Budaya keselamatan pasien merupakan sebuah aspek yang menentukan kualitas pelayanan sebuah institusi kesehatan. Keberhasilan institusi ini tidak saja tercermin melalui indikator capaian kinerja finansial dan tingkat kepuasan pelanggan, tetapi juga melalui seberapa institusi tersebut mengedepankan keselamatan pasien sebagai sebuah budaya titik Rumah Sakit memerlukan informasi mengenai sejauh mana keselamatan pasien sudah menjadi prioritas dan sejauh mana penerapan standar keselamatan pasien pada fasilitas pelayanan kesehatan.

Budaya keselamatan pasien adalah produk dari nilai, sikap, kompetensi dan pola perilaku individu dan kelompok yang menentukan komitmen, style dan kemampuan suatu organisasi pelayanan kesehatan terhadap program keselamatan pasien. Jika suatu organisasi pelayanan kesehatan tidak mempunyai budaya keselamatan pasien maka kecelakaan bisa terjadi akibat dari kesalahan laten, gangguan psikologis dan fisiologis pada staff penurunan produktivitas, berkurangnya kepuasan pasien dan menimbulkan konflik internal (Kemenkes, 2017).

Sasaran keselamatan pasien dalam peraturan Menteri Kesehatan Nomor 11 Tahun 2017, meliputi tercapainya hal-hal: mengidentifikasi pasien dengan benar, meningkatkan komunikasi yang efektif, meningkatkan keamanan obat-obatan yang harus diwaspadai, memastikan lokasi pembedahan yang benar, prosedur yang benar, pembedahan pada pasien yang benar, mengurangi risiko infeksi akibat perawatan kesehatan dan mengurangi risiko cedera pasien akibat terjatuh (Kemenkes, 2017). Tujuh langkah menuju keselamatan pasien terdiri atas: membangun kesadaran akan nilai kesamaan pasien, memimpin dan mendukung staf, mengintegrasikan aktivitas pengelolaan risiko, mengembangkan sistem pelaporan, 
melibatkan dan berkomunikasi dengan pasien, belajar dan berbagi pengalaman tentang keselamatan pasien, dan mencegah cedera melalui implementasi sistem keselamatan pasien (Kemenkes, 2017).

\section{METODE}

Kajian ini dilakukan dengan metode menganalisis dari berbagai sumber bacaan. Baik dari berbagai jurnal online, buku ataupun e-book, yang memiliki hubungan dengan Monitoring dan Evaluasi Budaya Keselamatan Pasien.

Penulisan kajian ini melakukan metode perbandingan antar satu artikel dengan artikel lainnya. Kemudian perbandingannya ditulis secara beraturan dalam hasil dari kajian. Dengan isi yang akan dibandingkan tetap berhubungan dengan Monitoring dan Evaluasi Budaya Keselamatan Pasien.

\section{HASIL}

Menurut hasil penelitian yang dilakukan Foster \& Rose dalam Yulia (2010) di UGD Rumah Sakit Pendidikan Otawa Kanada terhadap 399 pasien, didapatkan hasil Kejadian Tidak Diharapkan (KTD) sebanyak 24 kasus (6\%), Kejadian Tidak Diharapkan (KTD) dapat dicegah 17 kasus (71\%), Kejadian Tidak Diharapkan (KTD) tidak dapat dicegah 6 kasus (25\%), dan perpanjangan masa perawatan 15 kasus (62\%).

Laporan insiden keselamatan pasien di Indonesia oleh Komite Keselamatan Pasien Rumah Sakit Indonesia berdasarkan provinsi pada kuartal 1 periode Januari- April 2010 ditemukan provinsi Jawa Barat menempati urutan tertinggi sebesar 33,33\% diantara provinsi lainnya (Banten 20,0\%, Jawa Tengah 20,0\%, DKI Jakarta 16,67\%, Bali 6,67\%, Jawa Timur 3,37\%) (Komite Keselamatan Pasien RS, 2008).

Jika dilihat dari laporan Pengendalian Mutu dan Keselamatan Pasien (PMKP) Rumah Sakit Umum Daerah Provinsi Nusa Tenggara Barat tahun 2017 insiden keselamatan pasien masih terjadi di Rumah Sakit Umum Daerah Provinsi Nusa Tenggara Barat, diantaranya adalah Kejadian Nyaris Cidera (KNC) sebanyak 16 kasus (89\%) yang meliputi salah memberi resep sebanyak 2 kasus, salah membaca resep 2 kasus, salah memberikan obat sebanyak 7 kasus, obat expired date sebanyak 1 kasus, obat tertukar dengan pasien lain sebanyak 2 kasus dan salah menulis nama pada obat yang akan diberikan kepada pasien sebanyak 2 kasus, insiden keselamatan pasien yang masih terjadi satu lagi adalah Kejadian Potensi Cedera (KPC) sebanyak 2 kasus (11\%) yang kasusnya adalah air tumpah dari atap 
berwarna hitam sebanyak 1 kasus dan air tumpah dari plafon sebanyak 1 kasus. Dan untuk insiden keselamatan pasien lainnya seperti Kejadian Tidak Cedera (KTC), Kejadian Tidak Diharapkan (KTD) dan Sentinel sudah masuk dalam kategori baik karena tidak ada kasus yang terjadi selama tahun 2017 kemarin (Profil RS, 2018).

WHO (World Health Organization) tahun 2004 mengumpulkan angka-angka penelitian rumah sakit di berbagai Negara yaitu Amerika, Inggris, Denmark dan Australia dan ditemukan KTD (Kejadian Tidak Diharapkan) dengan rentang 3,2\% - 16,6\%. Sedangkan di New York KTD adalah sebesar 3,7\% dengan angka kematian 13,6 \%. Angka kematian akibat KTD pada pasien rawat inap di seluruh Amerika yang berjumlah 33,6 juta per tahun berkisar $44.000-98.000$ per tahun.

Di Indonesia berdasarkan data insiden keselamatan pasien yang diterbitkan KKPRS (Komite Keselamatan Pasien Rumah Sakit) terdapat 114 laporan insiden keselamatan pasien pada tahun 2009. 103 laporan pada tahun 2010, 34 m laporan pada tahun 2011 triwulan I.

Berdasarkan data kecelakaan pada tahun 2015 di ruang rawat inap RSU Anutapura Palu terdapat kecelakaan pasien yaitu kena pecahan ampula (39 kejadian), tertusuk jarum bekas pakai (8 kejadian), jatuh dari kursi (2 kejadian), terpeleset karena lantai licin (1 kejadian), kena pecahan tegel (1 kejadian), terpeleset dikamar mandi (1 kejadian), pasien jatuh dari tempat tidur (1 kejadian), tertusuk pinset (1 kejadian).

Survei Eurobarometer isu keselamatan pasien ditemukan 50\% dari responden di 27 negara anggota Uni Eropa mengatakan bahwa mereka mengalami Kejadian Tidak Diharapkan jika dirawat di rumah sakit. Yunani merupakan peringkat pertama yaitu $83 \%$ dan Latvia $75 \%$ sedangkan untuk Australia dan Jerman masing-masing 19\% dan 31\% pasien yang mengalami kerugian saat dirawat (Raftopoulos, 2013).

Berdasarkan data hasil penelitian terkait keselamatan pasien di Indonesia yang telah dilakukan oleh Nurmalia \& Nivalinda (2016) pada rumah sakit pemerintah di Semarang bahwa sebesar 56,2\% mentoring pelaksanaan keselamatan pasien masih kurang baik, sementara di rumah sakit swasta panti waluya sawahan malang oleh Harus B.D (2015) dilaporkan data Kejadian Tidak Diharapkan (KTD) 9 insiden (41\%), Kejadian Nyaris Cendera (KNC) 6 insiden (27\%), Kejadian Potensial Cedera (KPC) 5 insiden (23\%), Kejadian Tidak Cedera (KTC) 2 insiden (9\%). Data insiden keselamatan pasien masih banyak ditemukan baik di rumah sakit pemerintah maupun swasta meskipun telah lulus akreditasi, sehingga dapat menimbulkan dampak negatif terhadap pelayanan kesehatan. 
Survey lain yang juga dilakukan di Amerika Serikat terkait pelaksanaan budaya safety di rumah sakit oleh Agency Research Care and Quality (AHRQ) mengidentifikasi adanya angka yang rendah pada komunikasi terbuka (62\%), frekuensi pelaporan kejadian (60\%), kerjasama lintas unit (57\%), ketenagaan (55\%), operan (44\%), dan respon tidak menghukum terhadap kesalahan 44\% (Nazdam, 2009 dalam Setiowati, 2010).

\section{PEMBAHASAN}

Pelayanan keperawatan yang diberikan kepada pasien, dapat menimbulkan risiko keselamatan pasien yang begitu besar. Kejadian insiden keselamatan pasien yang terjadi di rumah sakit banyak yang tidak dilaporkan karena laporan yang diadakan tersebut akan dikaitkan dengan area kerja pada insiden yang terjadi. Hasilnya, para pengambil kebijakan di rumah sakit tidak mengetahui peringatan akan potensial terjadinya bahaya yang dapat menyebabkan error (Tamuz, et al, 2002).

Keselamatan pasien adalah proses dalam fasilitas pelayanan kesehatan yang memberikan pelayanan pasien secara aman. Proses tersebut meliputi pengkajian mengenai risiko identifikasi, manajemen risiko terhadap pasien, pelaporan dan analisis insiden, kemampuan untuk belajar dan menindaklanjuti insiden, dan menerapkan solusi untuk mengurangi serta meminimalisir timbulnya risiko.

Pelayanan kesehatan yang diberikan tenaga kesehatan kepada pasien mengacu kepada tujuh standar pelayanan pasien rumah sakit yang meliputi hak pasien, mendidik pasien dan keluarga, keselamatan pasien dan kesinambungan pelayanan, penggunaan metode-metode peningkatan kinerja untuk melakukan evaluasi dan program peningkatan keselamatan pasien, dan mendidik staf tentang keselamatan pasien, serta komunikasi merupakan kunci bagi staf untuk mencapai keselamatan pasien. Selain itu mengacu pada tahun standar pelayanan tersebut, keselamatan pasien juga dilindungi oleh undang-undang kesehatan sebagaimana yang diatur dalam UU Kesehatan Nomor 36 tahun 2009 serta UU Rumah Sakit Nomor 44 tahun 2009.

\section{A. Pengertian Budaya Keselamatan Pasien}

Secara umum budaya pasien safety dapat didefinisikan sebagai pola terpadu perilaku individu dan organisasi yang berorientasi pada nilai-nilai dan asumsi dasar yang terusmenerus berupaya meminimalkan kejadian-kejadian yang tidak diharapkan karena dapat membahayakan pasien. Patient safety culture adalah budaya rumah sakit yang berorientasi 
pada keselamatan pasien dengan kata lain bahwa layanan medis dijalankan secara profesional dan sangat careful agar AEs (Adverse Events) tidak terjadi. Budaya pasien safety akan menurunkan AEs secara signifikan sehingga akuntanbilitas di rumah sakit di mata pasien dan masyarakat akan meningkat sehingga akhirnya kinerja Rumah Sakit pun meningkat.

Budaya keselamatan pasien merupakan suatu kondisi di mana budaya organisasi mendukung dan mempromosikan keselamatan pasien. Budaya keselamatan pasien merujuk pada keyakinan nilai dan norma-norma yang ditujukan oleh praktisi pelayanan kesehatan dan staf lain dalam suatu organisasi yang mempengaruhi tindakan dan sikapnya. Budaya keselamatan pasien merupakan suatu yang bisa diukur dengan cara menghargai apa yang di lakukan oleh pegawai, dukungan yang diberikan dan penerimaan dari organisasi terhadap sesuatu yang terkait dengan keselamatan pasien (Sorra at all., 2016).

Menurut The health foundation, 2011 budaya keselamatan berkaitan dengan sejauh mana organisasi memprioritaskan dan mendukung peningkatan keselamatan dengan aman. Organisasi dengan budaya keselamatan positif memiliki komunikasi atas dasar saling percaya, persepsi bersama tentang pentingnya keselamatan, keyakinan pada efektivitas langkah-langkah pencegahan, dan dukungan bagi tenaga kerja.

\section{B. Sasaran Keselamatan Pasien Nasional}

Di Indonesia secara nasional untuk seluruh fasilitas pelayanan kesehatan, diberlakukan sasaran keselamatan pasien nasional yang terdiri dari:

SKP 1 : Mengidentifikasi pasien dengan benar. Kesalahan Karena keliru pasien sebenarnya terjadi di semua aspek diagnosis dan pengobatan. Keadaan yang dapat mengarahkan terjadinya kesalahan/error mengidentifikasi pasien, adalah pasien yang dalam keadaan terbius atau tersedasi, mengalami disorientasi, atau tidak sadar sepenuhnya; mungkin bertukar tempat tidur, kamar, lokasi di dalam fasilitas pelayanan kesehatan; mungkin mengalami disabilitas sensoris; atau akibat situasi lain.

SKP 2 : Meningkatkan an-nissa si yang efektif komunikasi yang efektif, tepat waktu, akurat, lengkap jelas dan yang dipahami oleh penerima, akan mengurangi kesalahan, dan menghasilkan peningkatan keselamatan pasien. Komunikasi dapat secara elektronik, lisan atau tertulis. Komunikasi yang paling mudah mengalami kesalahan adalah perintah diberikan secara lisan dan yang diberikan melalui telepon bila diperbolehkan peraturan perundangan komunikasi lain yang mudah terjadi kesalahan adalah pelaporan kembali hasil pemeriksaan 
kritis, seperti laboratorium klinis menelepon unit pelayanan pasien untuk melaporkan hasil pemeriksaan segera/cito.

SKP 3 : Meningkatkan keamanan obat-obat yang harus diwaspadai bila obat-obatan adalah bagian dari rencana pengobatan pasien, maka penerapan manajemen yang benar penting untuk memastikan keselamatan pasien. Obat-obatan yang perlu diwaspadai adalah obat yang presentasinya tinggi dalam menyebabkan terjadinya kesalahan dan kejadian Sentinel, obat yang beresiko tinggi menyebabkan dampak yang tidak diinginkan demikian pula dengan obat-obat yang tampak mirip (nama obat, rupa dan ucapan mirip).

SKP 4 : Memastikan lokasi pembedahan yang benar, prosedur yang benar, pembedahan pada pasien yang benar. Salah lokasi, salah prosedur, salah pasien operasi adalah kejadian yang mengkhawatirkan dan biasa terjadi di fasilitas pelayanan kesehatan. Kesalahan ini adalah akibat dari komunikasi yang tidak efektif atau tidak adekuat antara anggota tim bedah, kurang/tidak melibatkan pasien di dalam pelayanan penandaan lokasi, dan tidak ada prosedur untuk memverifikasi lokasi operasi. Disamping itu juga asesmen pasien yang tidak adekuat, penelaahan ulang catatan medis tidak adekuat, budaya yang tidak mendukung komunikasi terbuka antar anggota tim bedah, permasalahan yang berhubungan dengan resep yang tidak terbaca dan pemakaian singkatan adalah merupakan faktor-faktor kontribusi yang sering terjadi.

SKP 5 : Mengurangi risiko infeksi akibat perawatan kesehatan. Pencegahan dan pengendalian infeksi merupakan tantangan praktisi dalam kebanyakan tatanan pelayanan kesehatan, dan peningkatan biaya untuk mengatasi infeksi yang berhubungan dengan pelayanan kesehatan merupakan keprihatinan besar bagi pasien maupun para profesional pelayanan kesehatan. Infeksi umumnya dijumpai dalam semua bentuk pelayanan kesehatan termasuk infeksi saluran kemih terkait kateter infeksi aliran darah dan Pneumonia. Pokok dari eliminasi infeksi ini maupun infeksi lain adalah cuci tangan yang tepat. Pedoman hand hygiene yang berlaku secara internasional bisa diperoleh dari WHO, fasilitas pelayanan kesehatan mempunyai proses kolaboratif untuk mengembangkan kebijakan dan prosedur yang menyesuaikan atau mengadopsi pedoman hand hygiene yang diterima secara umum untuk implementasi pedoman di fasilitas pelayanan kesehatan.

SKP 6 : Mengurangi risiko cedera pasien akibat terjatuh. Jumlah kasus jatuh menjadi bagian yang bermakna penyebab cedera pasien rawat inap. Dalam konteks populasi atau masyarakat yang dilayani, pelayanan yang diberikan, dan fasilitasnya, fasilitas pelayanan kesehatan perlu 
mengevaluasi risiko pasien jatuh dan mengambil tindakan untuk mengurangi risiko cedera bila sampai jatuh. Evaluasi bisa meliputi riwayat jatuh, obat dan telaah terhadap obat dan konsumsi alkohol, penilaian terhadap gaya atau cara jalan, dan keseimbangan serta alat bantu berjalan yang digunakan oleh pasien. Program ini memonitor baik konsekuensi yang dimaksudkan atau yang tidak disengaja terhadap langkah-langkah yang dilakukan untuk mengurangi jatuh. Misalnya penggunaan yang tidak benar dari alat penghalang atau pembatas asupan cairan bisa menyebabkan cedera sirkulasi yang terganggu, atau integrasi kulit yang menurun. Program tersebut harus diterapkan di fasilitas pelayanan kesehatan.

C. Tujuh Langkah Menuju Keselamatan Pasien

1. Membangun kesadaran akan nilai ke selamatan pasien. Ciptakan budaya adil dan terbuka.

2. Memimpin dan mendukung staf. Tegakkan fokus yang kuat dan jelas tentang keselamatan pasien di seluruh fasilitas pelayanan kesehatan.

3. Mengintegrasikan aktivitas pengelolaan risiko. Bangun sistem dan proses untuk mengelola risiko dan mengidentifikasi kemungkinan terjadinya kesalahan.

4. Mengembangkan sistem pelaporan. Pastikan staf mudah untuk melaporkan insiden secara internal atau lokal dan eksternal atau nasional.

5. Melibatkan dan berkomunikasi dengan pasien. Kembangkan cara cara berkomunikasi secara terbuka dan mendengarkan pasien.

6. Belajar dan berbagi pengalaman tentang keselamatan pasien. Untuk menggunakan analisa Akar masalah guna pembelajaran tentang bagaimana dan mengapa terjadi insiden.

7. Mencegah cedera melalui implementasi sistem keselamatan pasien. Pembelajaran lewat perubahan-perubahan di dalam praktik, proses atau sistem. Untuk sistem yang sangat kompleks seperti fasilitas pelayanan kesehatan untuk mencapai hal-hal diatas dibutuhkan perubahan budaya dan komitmen tinggi bagi seluruh staf dalam waktu yang cukup lama.

\section{Penerapan 12 Dimensi Budaya Keselamatan Pasien}

Dimensi dalam budaya keselamatan pasien yaitu : (Sorra et al., 2016)

1. Keterbukaan komunikasi 
2. Feedback dan komunikasi tentang kesalahan yang terjadi

3. Frekuensi pelaporan kejadian

4. Handoff dan transisi

5. Dukungan organisasi untuk keselamatan pasien

6. Respon tidak menghakimi pada kesalahan yang dilakukan

7. Organizational learning - pembelajaran berkelanjutan

8. Persepsi keseluruhan mengenai keselamatan pasien

9. Staf yang cukup

10. Supervisor/ harapan manajer dan tindakan yang dilakukan untuk meningkatkan keselamatan pasien

11. Kerjasama lintas unit

12. Kerjasama antar unit / dalam unit.

\section{E. Monitoring dan Evaluasi Budaya Keselamatan Pasien}

Mengukur keselamatan bagaimanapun bukan semata-mata mengukur bahaya. Menilai keselamatan dengan apa yang telah terjadi di masa lalu, meski informatif, tidak dengan sendirinya memberitahu betapa bahagianya saat ini atau akan berada di masa depan. Keselamatan berkaitan dengan berbagai cara dimana sistem dapat gagal berfungsi, yang tentunya jauh lebih banyak daripada mode fungsi yang dapat diterima. Beberapa kegagalan ini mungkin sudah tidak asing lagi, bahkan bisa diprediksi, namun sistem ini mungkin juga tidak berfungsi dengan cara yang tidak terduga. Keselamatan sebagian dicapai dengan waspada terhadap gangguan, merespon dengan cepat untuk menjaga agar tetap berjalan lancar. Dokter perawat dan manajer keperawatan melakukan sepanjang waktu dalam perawatan kesehatan, mungkin lebih besar daripada industri lainnya.

\section{Dimensi Pengukuran dan Pemantauan Keselamatan}

Vincent, Burnett, \& Cartney (2013) mengelompokkan menjadi 5 dimensi :

a. Kerusakan masa lalu: mencakup tindakan psikologis dan fisik

b. Keandalan: mencakup ukuran perilaku dan sistem

c. Sensitifitas terhadap operasi: informasi dan kapasitas untuk memantau keselamatan setiap jam atau setiap hari

d. Antisipasi dan kesiapan: kemampuan mengantisipasi, dan bersiap menghadapi masalah 
e. Integrasi dan pembelajaran: kemampuan untuk merespon dan memperbaiki, informasi keselamatan

\section{Sistem Pelaporan}

Sistem pelaporan dalam perawatan kesehatan pada awalnya ditujukan untuk menyediakan sarana pengukuran dan pembelajaran baik dari kejadian buruk maupun masalah keselamatan lainnya. Hasil penelitian Vincent, Burnett \& Cartney (2013) menunjukkan bahwa sistem pelaporan rutin yang diterapkan di rumah sakit melewatkan sebagian besar insiden keselamatan pasien yang diidentifikasi berdasarkan catatan kasus dan hanya mendeteksi 5\% insiden yang mengakibatkan kerusakan pada pasien.

3. Pelaporan Kejadian yang Ditargetkan

Beberapa organisasi menggunakan laporan kejadian prospektif atau tertarget, seringkali untuk jangka waktu tertentu, untuk mengatasi masalah keamanan yang diketahui. Misalnya, dalam beberapa praktik keperawatan primer ada minggu-minggu tertentu ketika Setiap kejadian buruk dicatat. Dari sini, tak mungkin diminta untuk melaporkan masalah spesifik seperti kehilangan hasil tes berdasarkan target untuk bulan berikutnya (Australian Commission on Safety and Quality in Helathcare, 2010).

\section{Pelaporan Wajib 'Tidak Pernah Kejadian'}

Beberapa kejadian keselamatan jarang terjadi namun memiliki konsekuensi tragis misalnya kematian karena menyuntikkan obat intravena ke sumsum tulang belakang. Adalah peristiwa keselamatan yang paling menonjol dan paling mengganggu yang sesuai dengan kecelakaan dominan lainnya. Peristiwa-peristiwa tersebut dituangkan dalam daftar 28 'tidak pernah kejadian' yang disusun oleh forum mutu nasional Inggris pada tahun 2004 dan sejak diadopsi oleh banyak organisasi sebagai target keselamatan. Identifikasi kejadian langka namun mengerikan ini selalu bergantung pada pelaporan, setidaknya sampai cara yang dapat diandalkan untuk mencari rekam medis elektronik muncul.

5. Monitoring dan Evaluasi Dilakukan Oleh Komite Mutu dan Keselamatan Pasien

- Monitoring 6 sasaran keselamatan pasien menggunakan indikator mutu, yang mana pengambilan data dilakukan oleh petugas pengambil data mutu unit, yang kemudian dimasukkan dalam sismadak. 
- Monitoring tujuh langkah menuju keselamatan pasien dan 12 dimensi keselamatan pasien dengan menggunakan survei pada seluruh ruang lingkup penerapan budaya keselamatan pasien.

- Petugas penyiapan kebutuhan Survei adalah komite mutu dan keselamatan pasien.

- Petugas monitoring atau Survei adalah penanggung jawab pengambil data di setiap unit.

- Petugas analisa data adalah komite mutu dan keselamatan pasien.

- Petugas pembuat laporan pelaksanaan kegiatan komite mutu dan keselamatan pasien.

- Survey budaya keselamatan pasien menggunakan kuesioner dari HSOPC (Hospital Survey on Patient Safety Culture) yang dikembangkan oleh AHRQ (Agency for Healthcare Research and Quality) 2016 dan disesuaikan dengan kondisi rumah sakit.

\section{Waktu Pelaksanaan}

- Analisa 6 sasaran keselamatan pasien dilakukan setiap 3 bulan

- analisa 12 dimensi budaya keselamatan pasien dilakukan, setiap dimensi budaya keselamatan pasien

- Analisa dibuat menggunakan grafik

- Analisa mencakup analisa pencapaian dan permasalahan

- Hasil pengumpulan data dan analisa dilaporkan pada pimpinan atau direktur rumah sakit

\section{Melakukan Tindak Lanjut Perbaikan}

Data yang telah dianalisa, apabila sudah baik dipertahankan atau ditingkatkan, Namun apabila masih kurang dilakukan perbaikan.

\section{KESIMPULAN}

Pelayanan keperawatan yang diberikan kepada pasien, dapat menimbulkan risiko keselamatan pasien yang begitu besar. Keselamatan pasien adalah proses dalam fasilitas pelayanan kesehatan yang memberikan pelayanan pasien secara aman.

Standar budaya keselamatan pasien ini mencakup hak sebagai pasien, mendidik kepada pasien dan keluarga pasien, keselamatan pasien dan kesinambungan terhadap 
pelayanan kesehatan, peran kepemimpinan dalam meningkatkan keselamatan pasien, mendidik staf tentang keselamatan pasien, komunikasi merupakan peningkatan budaya kerja dalam melakukan Monitoring evaluasi dan program peningkatan budaya keselamatan kepada pasien (Morello, 2014).

Budaya keselamatan pasien merupakan suatu kondisi di mana budaya organisasi mendukung dan mempromosikan keselamatan pasien. Budaya keselamatan pasien merujuk pada keyakinan nilai dan norma-norma yang ditujukan oleh praktisi pelayanan kesehatan dan staf lain dalam suatu organisasi yang mempengaruhi tindakan dan sikapnya.

Menilai keselamatan dengan apa yang telah terjadi di masa lalu, meski informatif, tidak dengan sendirinya memberitahu betapa bahagianya saat ini atau akan berada di masa depan. Keselamatan berkaitan dengan berbagai cara dimana sistem dapat gagal berfungsi, yang tentunya jauh lebih banyak daripada mode fungsi yang dapat diterima.

\section{DAFTAR PUSTAKA}

1. Anggraeni,Dewi.,dkk.2014.Evaluasi Pelaksanaan Sistem Identifikasi Pasien di Instalasi Rawat Inap Rumah Sakit.jurnal Kedokteran Brawijaya, Vol 28 (1), 99-104.

2. Arini,Tantri.2018. budaya Keselamatan Pasien Berbasis Pemberdayaan Struktural Dengan Kepuasan Kerja Perawat [tesis]. Surabaya (ID): Program Studi Magister Keperawatan Fakultas Keperawatan Universitas Airlangga Surabaya.

3. Buhari,Basok.2019.Budaya Keselamatan Pasien Rumah Sakit Pemerintah dan Rumah Sakit Swasta di Kota Jambi.Jurnal 'Aisyiyah Medika, Vol 3 (1), 1-18.

4. Iriviranty,Afrisya.2015.Analisis Budaya Organisasi dan Budaya Keselamatan Pasien Sebagai Langkah Pengembangan Keselamatan Pasien di RSIA Budi Kemuliaan Tahun 2014.Jurnal ARSI, Vol 1 (3), 196-206.

5. Juniarti,Nanda Hani.,Ahmad Ahid Mudayana.2018. Penerapan Standar Keselamatan Pasien di Rumah Sakit Umum Daerah Provinsi Nusa Tenggara Barat.Jurnal Kesehatan Poltekkes Ternate, Vol 11 (2?), 93-108.

6. Napirah,Muh.Rayman.,dkk.2019. Evaluasi Kebijakan Keselamatan Pasien (Patient Safety) Pada Perawat di Rumah Sakit Umum Anutapura Kota Palu.Jurnal Kesehatan Masyarakat, Vol 10 (2), 65-72.

7. Purwaka,Bangun T.2018.Panduan Budaya Keselamatan Rumah Sakit. Madiun: Komite Mutu dan Keselamatan Pasien RSUD dr. Soedono Madiun. 
8. Simamora, R. H., \& Fathi, A. (2019). The Influence Of Training Handover Based SBAR Communication For Improving Patients Safety. Indian journal of public health research \& development, 10(9), 1280-1285. Promosi dan evaluasi penerapan Budaya Keselamatan pasien.

9. Tutiany.,dkk.2017.Bahan Ajar Keperawatan: Manajemen Keselamatan Pasien.Kementerian Kesehatan Republik Indonesiai.

10. Wati,Ni Made Nopita.,dkk.2018.Hubungan Supervisis Keperawatan Dengan Pelaksanaan Budaya Safety.Adi Husada Nursing Journal, Vol 4 (2), 56-65.

11. Yarnita,Yeni.2018. Analisis Hubungan Sikap Perawat Dengan Budaya Keselamatan Pasien di Ruang Rawat Inap RSUD Arifin Achmad Provinsi Riau.Jurnal Photon, Vol $8(2), 81-85$. 